\title{
AVALIAÇÃO DE UM SISTEMA DE IRRIGAÇÃO POR ASPERSÃO EM MALHA EM PASTAGEM
}

\author{
BERTOSSI, Ana Paula ${ }^{1}$ \\ MILEN, Larissa Cabral ${ }^{2}$ \\ HOTT, Marlla de Oliveira ${ }^{2}$ \\ RODRIGUES, Rogério Rangel ${ }^{2}$ \\ REIS, Edvaldo Fialho dos ${ }^{3}$
}

\begin{abstract}
RESUMO: Com o objetivo avaliar a eficiência e a uniformidade de um sistema de irrigação por aspersão em malha instalada em uma área de pastagem de Brachiaria brizantha cv. Marandu no município de Alegre-ES, a área entre quatro aspersores avaliados foi dividida em subáreas quadradas de aproximadamente $3 \mathrm{~m} \times 3 \mathrm{~m}$ e coletores foram instalados no centro de cada subárea, de forma que a lâmina coletada representasse sua precipitação. Após a montagem da malha de coletores, o sistema de irrigação foi ligado por um período de uma hora e os volumes coletados foram medidos. A uniformidade de aplicação de água do sistema foi estimada através do Coeficiente de Uniformidade de Christiansen e do Coeficiente de Uniformidade de Distribuição, além desses foram calculados a irrigação real necessária, a lâmina coletada, aplicada, as perdas do sistema, a eficiência de aplicação e a irrigação total necessária. Com base nos valores encontrados pode-se concluir que o projeto de irrigação avaliado apresentou uma uniformidade ruim de aplicação de água, a lâmina média aplicada no período avaliado foi superior a lâmina real necessária à cultura irrigada e a eficiência de aplicação de água do sistema encontra-se abaixo do recomendado pela literatura.
\end{abstract}

Palavras-chave: Uniformidade. Eficiência. Manejo de irrigação. Brachiaria brizantha cv. Marandu.

\section{EVALUATION OF AN IRRIGATION SYSTEM SPRINKLER LOOP IN PASTURES}

SUMMARY: Aiming to evaluate the efficiency and uniformity of a sprinkler irrigation system loop installed in an area of Brachiaria brizantha cv. Marandu in the municipality of Alegre, Espirito Santo state, the area between four sprinklers evaluated was divided into subareas square approximately $3 \mathrm{~m}$ x $3 \mathrm{~m}$ collectors were installed in the center of each area, so that the blade collected represented their precipitation. After mounting the mesh collector, the irrigation system was turned on for a period of one hour and the volumes collected were measured. The uniformity of water application system was estimated by Christiansen Coefficient of Uniformity and Distribution Uniformity Coefficient, and these were calculated irrigation real need, the blade collected, applied, system losses, the efficiency of application and total irrigation needed. Based on the values obtained it can be concluded that the irrigation project evaluated showed a poor uniformity of application of water, the middle layer applied during the evaluation period was higher than necessary for real blade and efficiency of irrigated water application system finds below that recommended by the literature.

Keywords: Uniformity. Efficiency. Irrigation management. Brachiaria brizantha cv. Marandu.

\section{INTRODUÇÃO}

Nos últimos anos a evolução da pecuária brasileira tem ampliado a participação da irrigação no agronegócio, fazendo com esta se torne cada vez mais uma estratégia importante para o aumento da produção, produtividade e rentabilidade da propriedade rural.

Segundo Drumond; Aguiar (2005), dentre os métodos de irrigação mais utilizados em pastagens, destacam-se os sistemas pressurizados, principalmente os sistemas de irrigação por aspersão, nos quais os mais

\footnotetext{
${ }^{1}$ Doutoranda em Produção Vegetal

${ }^{2}$ Mestranda em Produção Vegetal

${ }^{3}$ Departamento de Engenharia Rural
} 
usados são pivô central e a aspersão em malha.

No sistema de irrigação por aspersão em malha, as linhas laterais são interligadas em malha e enterradas, assim como a linha principal e a de derivação. Possui como características principais: baixo consumo de energia, possibilidade de divisão da área em várias subáreas, facilidade de operação e manutenção, possibilidade de fertirrigação e baixo custo de instalação e manutenção (DRUMOND; FERNANDES, 2004).

Uma vez instalado um projeto de irrigação, é necessário verificar se as condições previstas estão sendo atendidas no campo. Para tanto, deve-se avaliar as condições de pressão, vazão, lâminas d'água aplicadas e uniformidade de aplicação, entre outros parâmetros (MANTOVANI et al., 2009). No entanto, a avaliação do desempenho de sistemas de irrigação ainda não é realizada com muita frequência na maioria das propriedades.

O manejo racional de qualquer projeto de irrigação deve considerar aspectos sociais e ecológicos e procurar maximizar a produtividade, minimizar os custos, aumentar a eficiência no uso da água e da energia, mantendo as condições de umidade do solo favoráveis ao bom desenvolvimento da planta (PAZ et al., 2000).

A agricultura irrigada apresenta diversos benefícios que só podem ser alcançados em toda sua plenitude quando o sistema de irrigação for utilizado com critérios de manejo que resultem em aplicações de água de qualidade, no momento oportuno e nas quantidades compatíveis com as necessidades de consumo das culturas irrigadas, levando sempre em consideração a relação solo-planta-água-clima (DRUMOND, 2003).

Diante do exposto, o presente estudo teve como objetivo avaliar a eficiência e a uniformidade de um sistema de irrigação por aspersão em malha instalada em uma área de pastagem de Brachiaria brizantha cv. Marandu no município de Alegre-ES.

\section{MATERIAL E MÉTODOS}

A avaliação do sistema de irrigação foi realizada no mês de novembro de 2012 em uma área de 3,7 ha com cultivo de Brachiaria brizantha cv. Marandu localizada na área experimental do Instituto Federal do Espírito Santo - Campus de Alegre, no sul do estado do Espírito Santo situada sob as coordenadas geográficas 41 ${ }^{\circ} 32^{\prime}$ de longitude Oeste e $20^{\circ} 43^{\prime}$ de latitude Sul. Segundo a classificação de Köppen, o clima da região é do tipo Cwa, caracterizado pelo inverno seco e verão chuvoso, com precipitação média anual de $1400 \mathrm{~mm}$ e temperatura média anual entre $28^{\circ} \mathrm{C}$.

O sistema de irrigação utilizado foi o de aspersão em malha, composto de uma linha principal de 75 $\mathrm{mm}$ de diâmetro, duas linhas de derivação com diâmetro de $50 \mathrm{~mm}$ e 15 linhas laterais de $25 \mathrm{~mm}$ de diâmetro com aspersores por linha da marca NaanDanJain modelo 5035, 3/4"M e 1'”F, tipo rotativos de média pressão com bocais de 3,5 e $2,5 \mathrm{~mm}$, que segundo as especificações do fabricante tem diâmetro molhado de $26 \mathrm{~m}$ com vazão variando de 0,73 a $4,6 \mathrm{~m}^{3} \mathrm{~h}^{-1}$, pressão de serviço de 2,5 a 5,0 bar e intensidade de aplicação de $6,9 \mathrm{~mm}$ $\mathrm{h}^{-1}$. Os aspersores foram instalados a $1 \mathrm{~m}$ da superfície do solo no espaçamento de $18 \mathrm{~m}$ entre linhas e entre aspersores, operando sob gravidade. A irrigação da área é feita por um período de 3 horas quando o operador do sistema verifica visualmente que o solo se encontra seco ou na ausência de chuva.

Foram coletadas amostras de solo em diversos pontos dentro da área avaliada para a formação de uma amostra composta representativa da camada de $0-20 \mathrm{~cm}$ de profundidade, para a determinação da densidade do solo pelo método da proveta, umidade atual do solo pelo método-padrão de estufa e umidade do solo na capacidade de campo (Cc) e no ponto de murcha (Pm), com o auxílio do extrator de Richards de acordo com a metodologia da Embrapa (1997). As características do solo da área de avaliação estão apresentadas na tabela 1.

Tabela 1. Características físico-hídricas do solo, em que: $\mathrm{DS}=$ densidade, $\mathrm{U}=$ umidade atual, $\mathrm{CC}=$ umidade na capacidade de campo e PM= umidade no ponto de murcha

\begin{tabular}{cccc}
\hline $\mathrm{DS}\left(\mathrm{g} \mathrm{cm}^{-3}\right)$ & $\mathrm{Ua} \mathrm{( \% )}$ & $\mathbf{C C}(\boldsymbol{\%})$ & PM (\%) \\
\hline 1,19 & 10,55 & 13,5 & 6,6 \\
\hline
\end{tabular}

Nucleus, v.10, n.1, abr.2013 
A avaliação da uniformidade de aplicação de água do sistema de irrigação em estudo foi realizada de acordo com a metodologia de Christiansen (1942) citada por Mantovani (2009), e consistiu em coletar as precipitações por meio de coletores instalados em uma malha de pontos sob a área de influência de quatro aspersores $\left(420 \mathrm{~m}^{2}\right)$, que possuíam espaçamento de 20 x $21 \mathrm{~m}$.

Para a realização do estudo, a área entre os quatro aspersores avaliados foi dividida em subáreas quadradas de aproximadamente $3 \mathrm{~m} \mathrm{x} 3 \mathrm{~m}$. Os coletores foram instalados no centro de cada subárea, de forma que a lâmina coletada representasse sua precipitação.

Os coletores usados foram copos plásticos descartáveis transparentes, com diâmetro de 7,4 cm, o que corresponde a uma área de $43,01 \mathrm{~cm}^{2}$. Os coletores foram apoiados em suportes de vergalhão, que tinham na sua parte superior um semi-círculo para acomodação e apoio do coletor, que foram espalhados em 6 linhas, sendo 7 por linha, totalizando 42 coletores na área avaliada.

Após a montagem da malha de coletores, o sistema de irrigação foi ligado por um período de uma hora. Os volumes medidos nos coletores em $\mathrm{mL}$ foram convertidos em lâminas d'água $(\mathrm{mm})$, considerando a área do coletor, de acordo com a equação 1 .

$$
\operatorname{lâm}(\mathrm{mm})=\frac{l \mathrm{a} m(\mathrm{~mL})}{A \text { coletor }} * 10
$$

Em que:

$$
\begin{aligned}
& \text { Lâm }(\mathrm{mm})=\text { Lâmina coletada, } \mathrm{em} \mathrm{mm;} \\
& \text { Lâm }(\mathrm{mL})=\text { Lâmina coletada, } \mathrm{em} \mathrm{mL} ; \\
& \text { A coletor = área do coletor, } \mathrm{em} \mathrm{cm}^{2} .
\end{aligned}
$$

Durante o estudo, mediu-se a vazão dos bocais dos quatro aspersores avaliados, de maior e de menor diâmetro. Para a medição da vazão dos aspersores foi medido o volume aplicado por cada bocal em um determinado período de tempo, com auxílio de um recipiente de 20 litros, cronômetro, mangueiras, e proveta graduada, repetindo o processo por 3 vezes. Para determinação da pressão de serviço do aspersor, foi utilizado um manômetro para medir a pressão no bocal de maior diâmetro de cada um dos quatro aspersores avaliados.

A uniformidade de aplicação de água do sistema foi estimada através do Coeficiente de Uniformidade de Christiansen (CUC) e do Coeficiente de Uniformidade de Distribuição (CUD) determinados pelas equações 2 e 3, respectivamente descritas por BERNARDO et al. (2006) e MANTOVANI et al. (2009).

$$
\mathrm{CUC}=100 *\left(1-\frac{\sum_{i=1}^{\mathrm{n}}|\mathrm{Li}-\mathrm{Lm}|}{\mathrm{nLm}}\right)
$$

Em que:

CUC $=$ Coeficiente de Uniformidade de Christiansen, em \%;

$\mathrm{L}_{\mathrm{i}}=$ Lâmina de cada coletor "i", em mm;

$\mathrm{L}_{\mathrm{m}}=$ Lâmina média de todos os coletores, em mm;

$\mathrm{n}=$ Número de coletores.

$$
C U D=100 * \frac{L q_{25 \mathbf{x}}}{L m}
$$

Em que:

CUD = Coeficiente de Uniformidade de Distribuição, em \%;

$\mathrm{L}_{\mathrm{q} 25 \%}=$ Média de $25 \%$ dos menores valores de lâminas observadas nos coletores, em mm;

$\mathrm{L}_{\mathrm{m}}=$ Lâmina média de todos os coletores, em mm.

A interpretação dos valores dos coeficientes de uniformidade (CUC e CUD) baseou-se na metodologia apresentada por MANTOVANI (2001) apresentada na Tabela 2. 
Tabela 2. Classificação dos valores do desempenho dos sistemas de irrigação por aspersão em função do Coeficiente de Uniformidade de Christiansen (CUC) e do Coeficiente de Uniformidade de Distribuição (CUD)

\begin{tabular}{ccc}
\hline Classificação & CUC (\%) & CUD $(\boldsymbol{\%})$ \\
\hline Excelente & $>90$ & $>84$ \\
Bom & $80-90$ & $68-84$ \\
Razoável & $70-80$ & $52-68$ \\
Ruim & $60-70$ & $36-52$ \\
Inaceitável & $<60$ & $<36$ \\
\hline
\end{tabular}

Fonte: Mantovani (2001).

De posse dos resultados dos parâmetros físico-hídricos do solo da área em estudo, foi calculada a lâmina de irrigação real necessária (IRN) para elevar a umidade atual do solo à capacidade de campo, utilizando-se a equação 4, descrita por Mantovani et al. (2009).

$\mathrm{IRN}=\left(\frac{\mathrm{CC}-\mathrm{Ua}}{10}\right) * \mathrm{Da} * \mathrm{Z}$

Em que:

IRN = Irrigação real necessária, em mm;

$\mathrm{CC}=$ Umidade do solo na capacidade de campo, \% em peso;

$\mathrm{U}_{\mathrm{a}}=$ Umidade atual do solo, antes da irrigação, \% em peso;

$\mathrm{D}_{\mathrm{a}}=$ Densidade aparente do solo, $\mathrm{g} \mathrm{cm}^{-3}$;

$\mathrm{Z}=$ Profundidade efetiva do sistema radicular, $\mathrm{em} \mathrm{cm}$.

Foi utilizado valor de $Z=30 \mathrm{~cm}$ para o projeto em estudo, pois se entende que $90 \%$ das raízes das gramíneas se concentram nessa profundidade (VIEIRA, 1995).

Após a determinação da IRN, determinou-se a lâmina aplicada durante a irrigação por meio da equação 5 descrita por Mantovani et al. (2009).

$L_{a p l}=\frac{1.000 * Q * T}{S_{1} * S_{\mathbf{2}}}$

Em que:

$\mathrm{L}_{\mathrm{apl}}=$ Lâmina aplicada durante a irrigação, $\mathrm{mm}$;

$\mathrm{Q}=$ Vazão média do aspersor, $\mathrm{m}^{3} \mathrm{~h}^{-1}$;

$\mathrm{T}=$ Tempo de irrigação, $\mathrm{h}$;

$\mathrm{S}_{1}$.e $\mathrm{S}_{2}=$ Espaçamento entre aspersores: na linha lateral e entre linha lateral, $\mathrm{m} * \mathrm{~m}=\mathrm{m}^{2}$.

Determinou-se a lâmina média coletada $\left(\mathrm{L}_{\mathrm{col}}\right.$, em mm), as perdas por evaporação e arraste (Pev+ar, em \%), a lâmina média percolada ( $\mathrm{L}_{\mathrm{perc}}$, em $\mathrm{mm}$ ), a lâmina deficitária $\left(\mathrm{L}_{\mathrm{def}}, \mathrm{em} \mathrm{mm}\right)$, a lâmina armazenada ( $\mathrm{L}_{\mathrm{arm}}$, em $\mathrm{mm}$ ), a eficiência de aplicação de água pelo sistema de irrigação (Ea, em\%), a perda por percolação (Pper, em \%), o coeficiente de déficit $\left(\mathrm{C}_{\mathrm{d}}\right.$, em \%) e a Irrigação total necessária (ITN, em mm) através das equações 6 , $7,8,9,10,11,12,13$ e 14, respectivamente de acordo com a metodologia apresentada por Bernardo et al. (2006).

$L_{\mathrm{col}}=\frac{\sum L i}{n}$

Em que:

$\mathrm{L}_{\mathrm{col}}=$ Lâmina média coletada, $\mathrm{mm}$;

$\Sigma \mathrm{L}_{\mathrm{i}}=$ Somatório das lâminas coletadas, mm;

$\mathrm{n}=$ Número de coletores. 
Pev $+a r=\frac{\text { Lapl-Lool }}{\text { Lapl }}$

Em que:

Pev+ar = Perdas por evaporação e arraste, \%;

$\mathrm{L}_{\mathrm{apl}}=$ Lâmina aplicada durante a irrigação, mm;

$\mathrm{L}_{\mathrm{col}}=$ Lâmina média coletada, $\mathrm{mm}$.

$L_{p e r}=\frac{\sum_{i=\mathbf{1}}^{n}(L i-I R N)}{n}$ quando $\left(L_{i}-I R N\right)>0$

Em que:

$\mathrm{L}_{\text {perc }}=$ Lâmina média percolada, $\mathrm{mm}$;

$\mathrm{Li}=$ Lâminas coletadas, $\mathrm{mm}$;

IRN = Irrigação real necessária, $\mathrm{mm}$;

$\mathrm{n}=$ Número de aspersores avaliados.

$L_{\text {def }}=\frac{\sum_{i=\mathbf{1}}^{n}(L i-I R N)}{n}$ quando $\left(L_{i}-I R N\right)<0$

Em que:

$\mathrm{L}_{\mathrm{def}}=$ Lâmina deficitária, mm;

$\mathrm{Li}=$ Lâminas coletadas, $\mathrm{mm}$;

IRN = Irrigação real necessária, mm;

$\mathrm{n}=$ Número de aspersores avaliados.

$L_{\text {arm }}=I R N-L_{p e r c}$

Em que:

$\mathrm{L}_{\mathrm{arm}}=$ Lâmina armazenada na zona radicular, mm;

IRN = Irrigação real necessária, mm;

$\mathrm{L}_{\mathrm{perc}}=$ Lâmina média percolada, $\mathrm{mm}$.

$E_{a}=100 * \frac{L_{a r m}}{L_{a p l}}$

Em que:

Ea = Eficiência de aplicação de água pelo sistema de irrigação, \%;

$\mathrm{L}_{\mathrm{arm}}=$ Lâmina armazenada na zona radicular, mm;

$\mathrm{L}_{\mathrm{apl}}=\mathrm{Lâmina}$ aplicada durante a irrigação, $\mathrm{mm}$.

Pper $=100 *\left(\frac{\text { Lper }}{\text { Lapl }}\right)$

Em que:

Pper $=$ Perda por percolação, \%;

$\mathrm{L}_{\text {perc }}=$ Lâmina média percolada, $\mathrm{mm}$;

$\mathrm{L}_{\mathrm{apl}}=$ Lâmina aplicada durante a irrigação, $\mathrm{mm}$.

$C_{d}=100 * \frac{L_{\text {def }}}{I R N}$ 
Em que:

$\mathrm{C}_{\mathrm{d}}=$ Coeficiente de déficit, \%;

$\mathrm{L}_{\text {def }}=$ Lâmina deficitária, mm;

IRN = Irrigação real necessária, $\mathrm{mm}$.

$I T N=\frac{I R N+\left(p_{e v}+a r\right)}{E a}$

Em que:

ITN = Irrigação total necessária, mm;

IRN = Irrigação real necessária, mm;

Pev+ar = perda por evaporação e arraste;

$\mathrm{Ea}=$ Eficiência de aplicação.

\section{RESULTADOS E DISCUSSÃO}

$\mathrm{Na}$ avaliação do sistema foi constatada uma pressão de serviço de 28 mca no primeiro aspersor, e o mesmo valor foi observado nos demais aspersores. Este fato pode ser explicado devido a pequena extensão da linha lateral, e também devido ao bom estado das tubulações que não apresentavam vazamentos. Já as vazões medidas apresentaram uma pequena variação, mantendo-se próxima a média $\left(1962 \mathrm{~L} \mathrm{~h}^{-1}\right)$ e a vazão especificada pelo fabricante, que foi de $2000 \mathrm{~L} \mathrm{~h}^{-1}$ (Figura 1).

Segundo Alencar et al. (2009) quando um projeto de irrigação apresenta aspersores funcionando com diferentes pressões de serviço, diferentes vazões serão aplicadas e consequentemente menores uniformidades de aplicação de água serão observadas. Como no presente estudo as pressões dos aspersores avaliados eram iguais, observou-se pequena variação na vazão aplicada.

Figura 1. Distribuição da vazão dos aspersores avaliados.

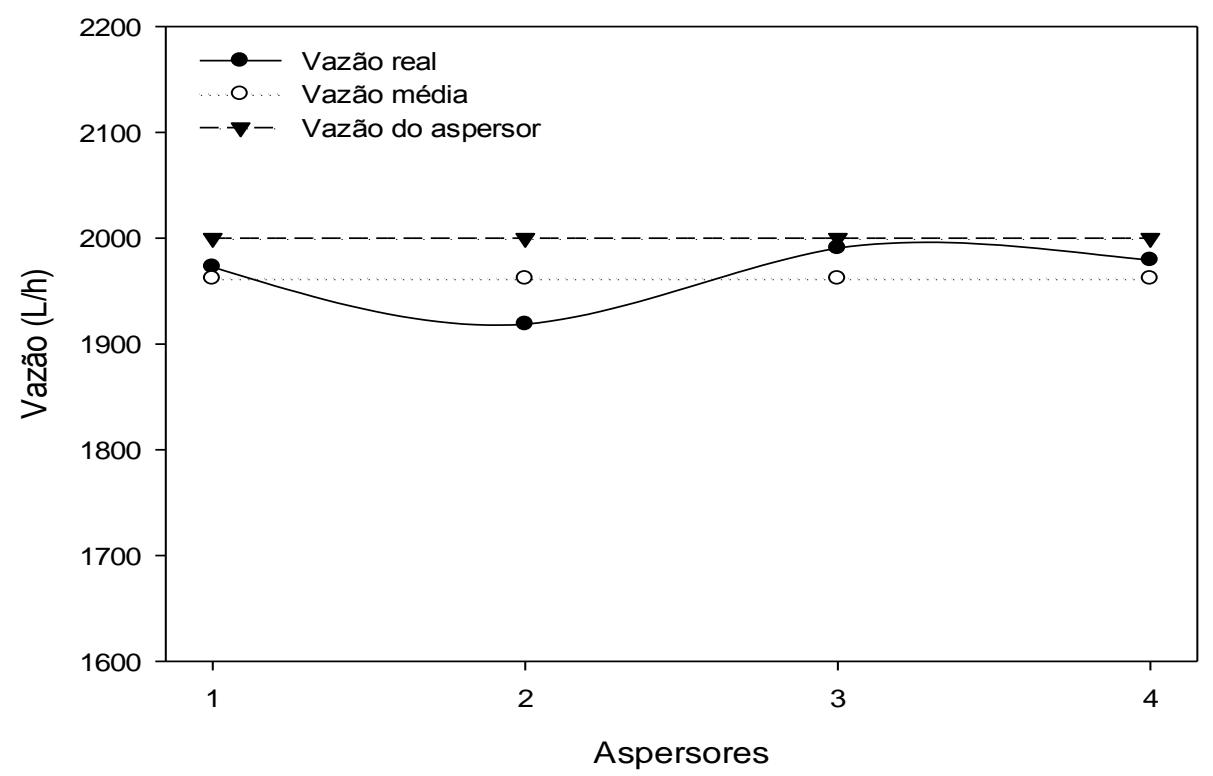

As lâminas coletadas durante o período de avaliação do sistema estão apresentadas na Tabela 3, na qual se percebe uma grande variação entre os valores medidos, que variaram de $0,47 \mathrm{~mm}$ a $8,14 \mathrm{~mm}$, com média de 3,96 $\mathrm{mm}$. Durante a avaliação pode-se observar que não havia sobreposição dos jatos d'água dos aspersores, tendo estes aproximadamente $11 \mathrm{~m}$ de alcance, sendo encontradas lâminas maiores nas bordas do 
quadrante, próximo aos aspersores e menores no centro. Essa má distribuição de água também pode ser observada na Figura 2, que expressa a distribuição das lâminas de água coletadas durante a avaliação do sistema por aspersão em malha na pastagem.

Tabela 3. Lâminas (mm) coletadas durante uma hora de avaliação do sistema de irrigação por aspersão em malha

\begin{tabular}{lllllll}
\hline 5,58 & 5,12 & 5,35 & 3,26 & 2,79 & 5,12 & 7,44 \\
5,58 & 4,65 & 3,49 & 2,56 & 3,26 & 2,33 & 4,88 \\
3,95 & 2,79 & 2,09 & 3,26 & 2,79 & 2,09 & 2,33 \\
4,65 & 4,19 & 3,26 & 2,33 & 1,86 & 1,16 & 2,33 \\
5,58 & 4,42 & 3,26 & 2,09 & 0,47 & 2,79 & 6,05 \\
8,14 & 6,98 & 6,51 & 2,79 & 2,09 & 6,98 & 7,91 \\
\hline
\end{tabular}

Figura 2. Distribuição das lâminas aplicadas durante a avaliação do sistema por aspersão em malha.
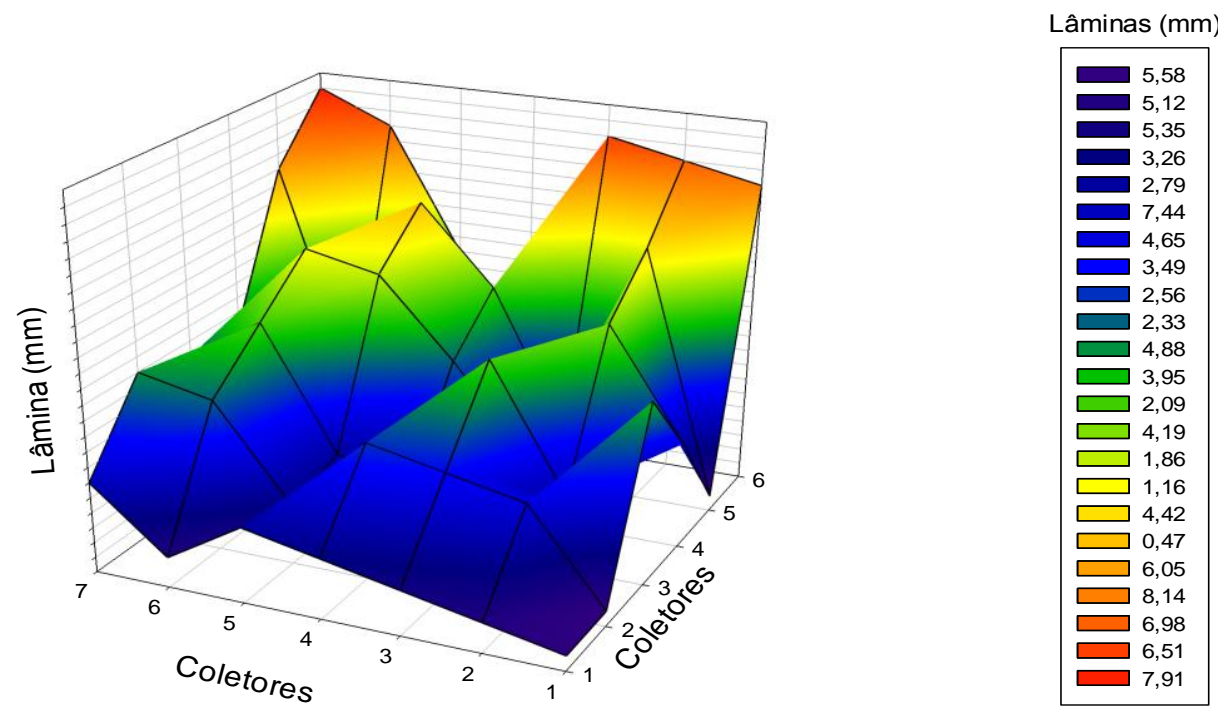

A grande variação encontrada nas lâminas pode ser atestada pelos valores do Coeficiente de Uniformidade de Christiansen (CUC) e do Coeficiente de Uniformidade de Distribuição (CUD), que foram muito baixos, sendo classificados de acordo com Mantovani (2001) como inaceitável e ruim, respectivamente (Tabela 4).

Tabela 4. Valores e classificação do Coeficiente de Uniformidade de Christiansen (CUC) e do Coeficiente de Uniformidade de Distribuição (CUD)

\begin{tabular}{l|cc}
\hline Coeficientes & Valor & Classificação \\
\hline CUC $(\%)$ & 59,5 & Inaceitável \\
CUD $(\%)$ & 48,5 & Ruim \\
\hline
\end{tabular}

De acordo com Bernardo et al. (2006) projetos de irrigação por aspersão devem apresentar coeficientes de uniformidade da ordem de 75 a $90 \%$, o que resultaria em boa distribuição espacial de água e consequentemente maior uniformidade da lavoura, o que não foi observado no sistema avaliado, no qual apenas 59,5 \% da área está recebendo uma lâmina maior ou igual à lâmina média de aplicação e nos pontos onde foram coletados as menores lâminas pode-se observar um amarelecimento do capim. 
O CUD relaciona as menores lâminas aplicadas da área total (quartil que recebe menos água). Um baixo valor de CUD indica que uma excessiva perda por percolação profunda ocorreria se toda a área recebesse uma lâmina maior ou igual à real necessária, o que pode acontecer na área, já que o valor de CUD encontrado foi muito baixo.

Paulino et al. (2009) e Martins et al. (2011) ao avaliarem o desempenho de sistemas de irrigação por aspersão convencional também observaram baixa uniformidade de aplicação de água nos projetos avaliados, atribuindo os baixos valores de CUC e CUD ao mau dimensionamento do projeto e a ausência de manejo do sistema, o que também foi observado no presente estudo.

Uma das consequências diretas de uma baixa uniformidade de aplicação de água, em um sistema de irrigação, é o aumento do volume de água aplicado. Para que as plantas que recebem menor lâmina recebam quantidade suficiente para seu desenvolvimento, deve-se aumentar a lâmina aplicada. Isto faz com que as demais plantas recebam excesso de água, que se perderá por percolação profunda (LÓPEZ et al., 1992).

Na Tabela 5 estão apresentados os valores da Irrigação real necessária (IRN), lâmina média aplicada (Lmapl), lâmina média coletada (Lmcol), perdas por evaporação e arraste (Pev+ar), lâmina percolada (Lper), lâmina deficitária (Ldef), lâmina armazenada na zona radicular (Larm), eficiência de aplicação (Ea), perdas por percolação (Pper), coeficiente de déficit $(\mathrm{Cd})$ e Irrigação total necessária (ITN) do projeto de irrigação avaliado.

Tabela 5. Valores da Irrigação real necessária (IRN), lâmina média aplicada (Lmapl), lâmina média coletada (Lmcol), perdas por evaporação e arraste (Pev+ar), lâmina percolada (Lper), lâmina deficitária (Ldef), lâmina armazenada na zona radicular (Larm), eficiência de aplicação (Ea), perdas por percolação (Pper), coeficiente de déficit (Cd) e Irrigação total necessária (ITN)

\begin{tabular}{ccccccccccc}
\hline $\begin{array}{c}\text { IRN } \\
(\mathbf{m m})\end{array}$ & $\begin{array}{c}\text { Lmapl } \\
(\mathbf{m m})\end{array}$ & $\begin{array}{c}\text { Lmcol } \\
(\mathbf{m m})\end{array}$ & $\begin{array}{c}\text { Pev+ar } \\
(\boldsymbol{\%})\end{array}$ & $\begin{array}{c}\text { Lperc } \\
(\mathbf{m m})\end{array}$ & $\begin{array}{c}\text { Ldef } \\
(\mathbf{m m})\end{array}$ & $\begin{array}{c}\text { Larm } \\
(\mathbf{m m})\end{array}$ & $\begin{array}{c}\text { Ea } \\
(\boldsymbol{\%})\end{array}$ & $\begin{array}{c}\text { Pper } \\
(\boldsymbol{\%})\end{array}$ & $\begin{array}{c}\text { Cd } \\
(\boldsymbol{\%})\end{array}$ & $\begin{array}{c}\text { ITN } \\
(\mathbf{m m})\end{array}$ \\
\hline 10,53 & 14,01 & 11,89 & 15,13 & 6,69 & 3,04 & 5,20 & 37,14 & 47,71 & 28,87 & 32,66 \\
\hline
\end{tabular}

De acordo a tabela 5 verifica-se que a lâmina média aplicada no período avaliado foi superior a irrigação real necessária (IRN). Devido a má distribuição de água aplicada na área, pode-se observar locais que receberam uma lâmina de água maior que a IRN, indicando um irrigação excessiva, o que propiciou uma lâmina média percolada de 6,69 mm, equivalente a 47,71 \% de perdas de água por percolação profunda, ocasionando consequentemente perdas de nutrientes por lixiviação e desperdício de água e de energia elétrica. Já outros locais apresentaram uma lâmina menor que a IRN, indicando uma irrigação deficitária de 3,04 mm, que representou um coeficiente de déficit de $28,87 \%$ e a lâmina que ficou armazenada no solo foi de 5,2 mm.

$\mathrm{Na}$ Figura 3, também se observa que a lâmina média aplicada foi superior a IRN, e a lâmina média coletada menor que a aplicada, essa diferença representa as perdas por evaporação e arraste, que foram de 15,13 \% (Tabela 5). Analisando o volume coletado durante a avaliação pode-se notar que aproximadamente $50 \%$ da área recebeu uma lâmina menor que a IRN, podendo haver um déficit de água no local, assim como a outra metade recebeu água acima da IRN, podendo haver perdas por percolação.

Martins et al. (2011) ao avaliarem o desempenho de sistemas de irrigação por aspersão convencional na cultura do milho observaram que em todos os sistemas de irrigação por aspersão convencional em estudo a lâmina de irrigação aplicada (Lapl) também foi maior que a lâmina real necessária (IRN), indicando que todos os projetos em estudo aplicavam água em excesso, apresentando, portanto, baixa eficiência de aplicação. Já Souza et al. (2008), em sistema de irrigação por aspersão convencional instalado na Vila Rural Flor do Campo, localizada na região Noroeste do Estado do Paraná, observaram que a lâmina aplicada foi inferior à lâmina real necessária, indicando que a irrigação foi deficitária. 
Figura 3. Relação entre Irrigação real necessária (IRN), Volume coletado, Lâmina média aplicada (Lm apl) e coletada (Lm col) em um tempo de irrigação de 3 horas.

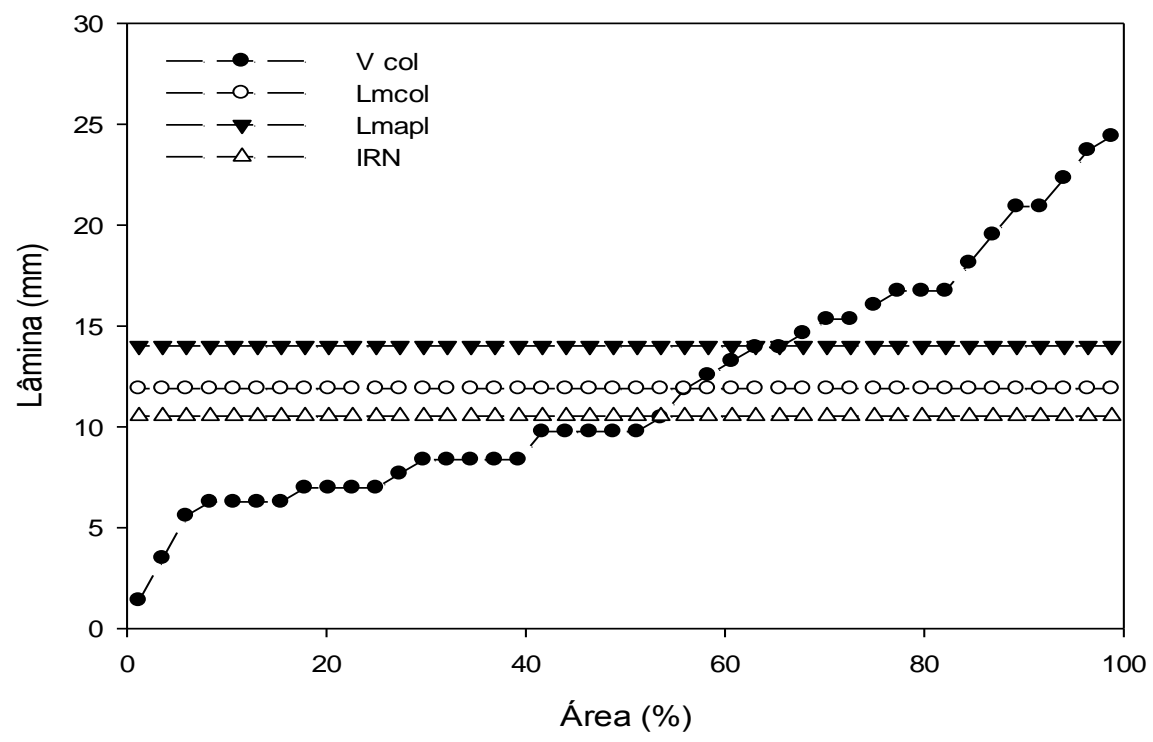

A produtividade agrícola em áreas irrigadas depende de vários fatores, dentre os quais, destacam-se o dimensionamento e o manejo dos sistemas de irrigação utilizados. A irrigação em excesso ou deficitária prejudica o desenvolvimento das plantas, por isso, é fundamental avaliar os sistemas de irrigação periodicamente, a fim de melhorar a uniformidade de distribuição e a eficiência de aplicação de água para minimizar as perdas de água, energia elétrica e de fertilizantes (SILVA e SILVA, 2005).

Quanto à eficiência de aplicação de água (Ea), verifica-se que o projeto tem uma eficiência de $37,14 \%$ (Tabela 5). A eficiência de aplicação é obtida pela relação entre a quantidade de água armazenada no sistema radicular e a quantidade de água aplicada, por isso a baixa eficiência do sistema, já que a água armazenada foi pouco em relação à aplicada. $\mathrm{O}$ valor encontrado está bem abaixo do recomendado pela literatura para sistemas de irrigação por aspersão, que varia de 75-85\% (BERNARDO et al., 2006).

De acordo com Bernardo et al. (2006), quando um projeto de irrigação apresenta uma baixa eficiência de aplicação ou valor inferior ao recomendado pela literatura, o agricultor possivelmente terá problemas na produtividade e rentabilidade da cultura, além de possíveis problemas no solo.

O valor de ITN encontrado (Tabela 5) está bem acima da IRN, já que seu cálculo leva em consideração as perdas por evaporação e arraste e a eficiência do sistema que foi baixa, fazendo com que o valor da irrigação total seja alto a fim de compensar a má distribuição de água na área.

\section{CONCLUSÃO}

Com base nos resultados encontrados pode-se concluir:

- O projeto de irrigação avaliado apresentou uma uniformidade ruim de aplicação de água.

- A lâmina média aplicada no período avaliado foi superior a lâmina real necessária à cultura irrigada.

- A eficiência de aplicação de água do sistema encontra-se abaixo do recomendado pela literatura.

\section{REFERÊNCIAS}

ALENCAR, C. A. B.et al. Irrigação de pastagem: atualidade e recomendações para uso e manejo. R. Bras.

Zootec., Viçosa, v. 38, 2009 
BERNARDO, S.; SOARES, A. A.; MANTOVANI, E. C. Manual de Irrigação. 8.ed. Viçosa: UFV, 2006. 625 p.

DRUMOND, L. C. D. Aplicação de água residuária de suinocultura por aspersão em malha: desempenho hidráulico e produção de matéria seca de Tifton 85. 2003, 102f. Tese (Doutorado em Agronomia) - Faculdade de Ciências Agrárias e Veterinárias, Universidade Estadual Paulista, Jaboticabal.

DRUMOND, L. C. D.; FERNANDES, A. L. T. Irrigação por aspersão em malha para cafeicultura familiar. Uberaba: UNIUBE, 2004. 88p.

DRUMOND, L. C. D.; AGUIAR, A. P. A. Irrigação de pastagem. Uberaba: L.C.D.DRUMOND, 2005. 210p.

EMBRAPA - EMPRESA BRASILEIRA DE PESQUISA AGROPECUÁRIA. Manual de métodos de análise de solo. Centro Nacional de Pesquisa de Solos. Rio de Janeiro: EMBRAPA-CNPS, 1997. 212p.

LÓPEZ, R. J.et al. Riego localizado. Madrid: Mundi-Prensa, 1992. 405p.

MANTOVANI, E. C. AVALIA: Programa de Avaliação da Irrigação por Aspersão e Localizada. Viçosa, MG: UFV. 2001.

MANTOVANI, E. C.; BERNARDO, S.; PALARETTI, L. F. Irrigação, princípios e métodos. 3.ed. atual. ampl. Viçosa: UFV. 2009. 355p.

MARTINS, C. A. S.et al. Desempenho de sistemas de irrigação por aspersão convencional na cultura do milho (Zea mays L.). Idesia, v. 29, v. 3. p. 65-74, 2011.

PAULINO, M. A. O.et al. Avaliação da uniformidade e eficiência de aplicação de água em sistemas de irrigação por aspersão convencional. Revista Brasileira de Agricultura Irrigada, v.3, n.2, p.48-54, 2009.

PAZ, V. P. S.; TEODORO, R. E. F.; MENDONÇA, F. C. Recursos hídricos, agricultura irrigada e meio ambiente. Revista Brasileira de Engenharia Agrícola e Ambiental, v. 4, n. 3, p. 465-473, 2000.

SILVA, C. A. da; SILVA, C. J. Avaliação de uniformidade em sistemas de irrigação localizada. Revista Científica Eletrônica de Agronomia, ano 4, n. 8, 2005.

SOUZA, E.A.M. DE; SOUZA, P.C. DE.; BOAS, M.A.V. Avaliação do desempenho de sistemas de irrigação por aspersão convencional fixo e gotejamento em vila rural. Irriga, Botucatu, v.13, n.1, p.47-62, 2008.

VIEIRA, D. B. As técnicas de irrigação. 2 ed. São Paulo: Globo, 1995. 263 p. 